\title{
Impacts of the Cedar Avenue Driver Assist System on Bus Shoulder Operations
}

\author{
Brian Pessaro, University of South Florida
}

\begin{abstract}
This paper summarizes the first comprehensive evaluation of vehicle assist and automation (VAA) technology in bus revenue service by a U.S. transit agency. The technology in question is a GPS-based technology suite used by the Minnesota Valley Transit Authority for vehicle guidance in the shoulder. Called the Driver Assist System, or DAS, it provides accurate lane position feedback to the driver via a headup display, virtual mirror, vibrating seat, and actuated steering. The evaluation confirmed that the DAS improved bus operations and reduced driver stress. Drivers stayed in the shoulders 4.3 percent longer, drove 3.5 miles per hour faster, and reduced their side-to-side movement by 4.7 inches when the DAS was activated. The changes in speed and side-to-side movement were statistically significant at the $95 \%$ confidence level. In surveys, a majority of the drivers believed the DAS made driving in the shoulder safer and less stressful.

\section{Literature Review}

The Driver Assist System (DAS) installed on the buses of the Minnesota Valley Transit Authority (MVTA) is a form of vehicle assist and automation (VAA) technology. The purpose behind VAA is to create an "intelligent" vehicle that is capable of understanding the environment around it. VAA can be categorized into systems that provide collision warning to the driver, systems that take partial control of the vehicle, and systems that take full control of the vehicle (Bishop 2000). They can
\end{abstract}


be categorized further according to the type of control they provide. Longitudinal control can take the form of adaptive cruise control and forward collision warning systems. Lateral control can take the form of warning systems for lane departure, side obstacles, curve negotiation, and speed (Furukawa 2000).

Two primary uses of VAA in transit service are precision docking and lateral guidance (i.e., lane-keeping). The theoretical benefit of precision docking is that it improves the amenity value of bus transit by minimizing boarding times and the gap distance between the bus and station platform (Shladover and Miller 2004). The theoretical benefit of lateral guidance is that the bus is able to operate in narrow lanes (such as highway shoulders) that would otherwise be impractical. This would enable full speed operations in places where the bus would otherwise have to slow down, and it would reduce construction and right-of-way costs for new busways (Shladover and Miller 2004). VAA technologies, in general, have the potential to enhance safety by reducing visual demand on the driver's attention and improving reaction times (Griffiths and Gillespie 2004). Surveys of bus drivers in Rouen, France, confirm that the optical guidance system in use there has resulted in reduced stress (Shladover et al. 2007).

Research on the impacts of VAA to transit service is an emerging, but largely untapped, field. VAA research to date has relied on computer simulations (Brown, Moeckli, and Marshall 2009; Griffiths and Gillespie 2004), cost-benefit analyses using theoretical assumptions (Hardy and Proper 2006; Shladover and Miller 2004), and fact-finding tours of a few European transit systems that use VAA (Shladover et al. 2007). No empirical studies were found that evaluated the impacts of VAA on bus transit service. Much of this is due to the fact that there is very limited application of VAA worldwide. Almost all applications of VAA have been outside the United States. In Rouen, the TEOR transit system has used an optical guidance system for lanekeeping and precision docking since 2001 (Levinson et al. 2003). Mechanical guidance has been used on Fulerumer Straße in Essen, Germany, since 1980 (Boegner and Koch 1984), the O-bahn busway in Adelaide, Australia since 1986, and on the Superbus in Leeds, England, since 1995 (Levinson et al. 2003). Since 2004, the city of Eindhoven in the Netherlands has used magnetic guidance for precision docking on the Phileas bus rapid transit (BRT) system (APTS 2011). VAA applications in the United States have been limited mostly to field testing (Tan 2008). The only revenue service applications of VAA in the U.S., other than the DAS, was a brief application of an optical guidance system (OGS) by the MAX BRT transit in Las Vegas (Kim, Darido, and Schneck 2005) and mechanical guidance used by the HealthLine BRT in Cleveland (Pessaro 2011). 
The mechanical guidance used by the HealthLine is still in operation today. The optical guidance system on the MAX was discontinued due to the extensive maintenance required to keep pavement markings clean and therefore readable by the OGS (Kim, Darido, and Schneck, 2005).

\section{Driver Assist System Description}

In November 2010, MVTA implemented the Driver Assist System (DAS) for bus shoulder operations on Cedar Avenue (Trunk Highway 77). The DAS is a GPS-based technology suite that provides accurate lane position feedback to the bus driver. It includes a head-up display (HUD) mounted at eye level in front of the driver that digitally displays the shoulder boundaries under all weather conditions. Other features include a virtual mirror that digitally displays vehicles in the left adjacent lane, a vibrating seat that simulates the sensation of a rumble strip, and a steering activator that provides mild corrective torque to the steering wheel when the bus drifts over the fog line. Some of the DAS features are illustrated in Figure 1. MVTA's primary goal for the DAS was to enhance driver confidence in the shoulders. Secondary goals included reducing travel times and increasing reliability, safety, and customer satisfaction.

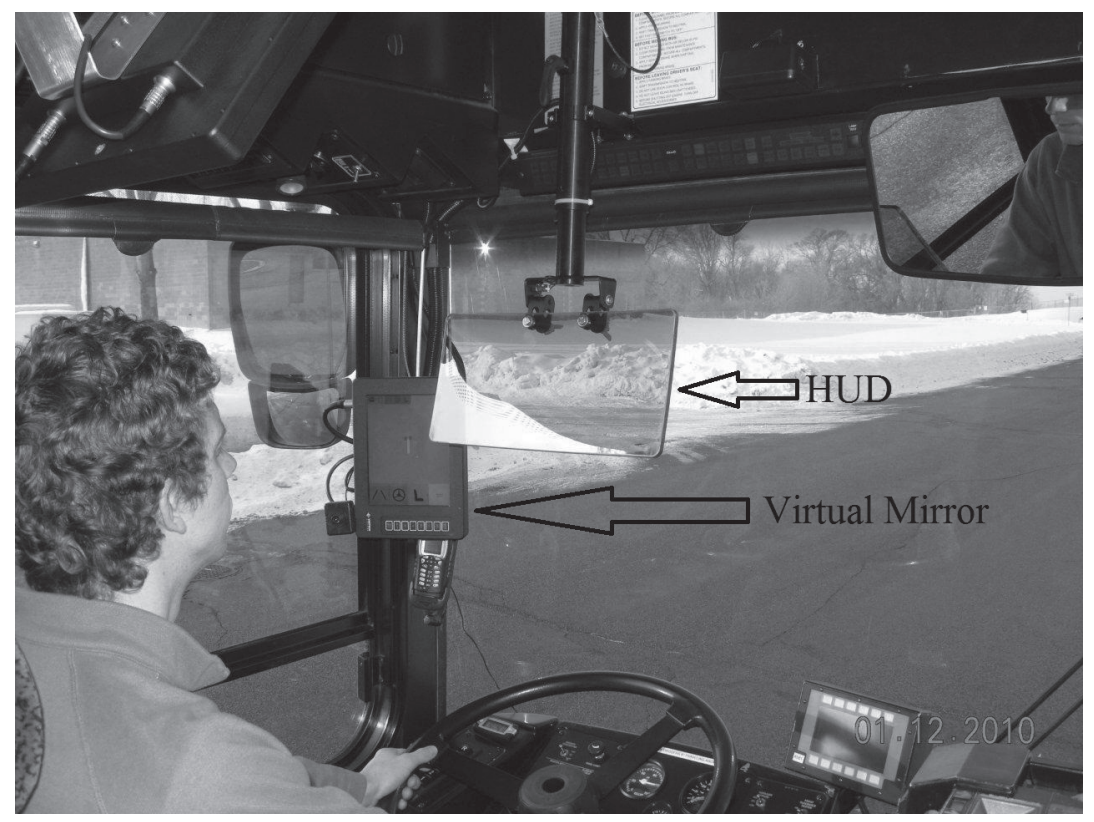

Figure 1. View of MVTA Driver Assist System (DAS) 


\section{Methodology}

The evaluation looked at six broad areas: efficiency/productivity, technical performance, bus driver satisfaction, customer satisfaction, safety, and maintenance. It involved two test periods; the first was from March 5-25, 2011, when the DAS was set to passive mode. During this time, use of the DAS was not available to the bus driver. However, the onboard computer was still collecting lane position and speed data. The second test period was from March 26-April 30 when the DAS was switched to active mode. The month evaluation period was a compromise from the original plan to collect six months' worth of data. This compromise was necessitated by three events. First, MVTA had to unexpectedly resolve liability issues with its contracted operator's insurance agency. While those negotiations were occurring, MVTA was required to completely disengage the DAS from the buses. The negotiations were completed around September 2010, and revenue operations with the DAS began in October. Unfortunately, much of the original baseline data had been lost after the DAS was disengaged. A second event occurred when it was discovered that a major driver "pick/shake-up" would take place on March 5, 2011. Because it was important to use the same drivers throughout the evaluation, MVTA recommended postponing the evaluation until after March 5 . The third event was securing the permission of the MVTA Board of Directors to switch the DAS to passive mode and collect baseline data. By March 2011, the DAS had been in service for six months. The MVTA Board was concerned that switching the DAS to passive mode could negatively impact customer service. In the end, March 5-25 was the maximum amount of time the Board would allow the DAS to be switched to passive mode.

To develop a sound methodology for the evaluation, several challenges had to be addressed. The first challenge was making sure the results would not be tainted by driver inexperience with the DAS. This challenge was addressed through training. MVTA required all drivers who chose routes with DAS-equipped buses to go through a month of training both in a simulator and on the road. By the time of the evaluation, all the drivers had adapted to using the DAS. A second challenge was controlling for individual driving behavior. To address this, the same pool of drivers was used during both test periods. The third challenge was that use of the shoulder is restricted to when speeds in the general-purpose lanes drop below $35 \mathrm{mph}$. Even then, the decision to use the shoulder is left to the discretion of the bus driver. This means there is no guarantee that on any given day a bus driver will use the shoulder. To address this challenge, drivers were included in the analysis only if they used the shoulder during both test periods. Unfortunately, this reduced the number of driv- 
ers that could be included in the study from 25 to 6 . In other words, there were 25 drivers who drove a DAS-equipped bus at some point in the evaluation, but only 6 used the shoulder during both test periods. During the evaluation period with the DAS in passive mode, 25 trips in the shoulder were recorded, and 44 were reported during the evaluation period with the DAS in active mode (see Table 1).

\section{Table 1. Number of Trips Recorded}

\begin{tabular}{|c|c|c|}
\hline Driver & DAS Off & DAS On \\
\hline 1 & 4 & 11 \\
\hline 2 & 3 & 4 \\
\hline 3 & 4 & 4 \\
\hline 4 & 6 & 8 \\
\hline 5 & 3 & 9 \\
\hline 6 & 5 & 8 \\
\hline Total & $\mathbf{2 5}$ & $\mathbf{4 4}$ \\
\hline
\end{tabular}

The evaluation included an independent samples $T$ test on several performance measures and the calculation of $p$ values. It was not possible to calculate $p$ values for each individual driver because some of them had very few trips. However, it was possible to calculate $p$ values for the composite results with the DAS on and off.

The evaluation also included soliciting feedback from bus drivers and passengers via surveys and focus groups. All 25 DAS-trained bus drivers completed a survey, and 16 participated in 2 focus groups. A passenger survey was distributed on all DAS-equipped buses; 135 surveys from 457 recorded passengers were completed, resulting in a response rate of 29.5 percent. The margin of error was \pm 7 percentage points at the $95 \%$ confidence level. The DAS's impacts on safety were measured by comparing the accident data of the DAS-equipped buses for the first six months of operations to the same six months of the previous year. Additionally, the drivers were asked about their perceptions of safety. The level of effort to maintain the DAS was evaluated by examining the maintenance logs kept by the DAS integrator, the Intelligent Vehicles Laboratory at the University of Minnesota.

\section{Results}

\section{Efficiency and Productivity}

This part of the evaluation looked at changes in shoulder usage and bus speeds. For shoulder usage, the measure of performance was the percentage of total available 
shoulder used. There was 9,055 feet $(2,760 \mathrm{~m})$ of available shoulder on the test segment. If a bus stayed in the shoulder for all 9,055 feet on any given trip, it used 100 percent of the shoulder. The logic behind this measure is that the more confident a driver feels in the shoulder, the greater percentage of the shoulder he/she will use. Table 2 shows the percentage of the total available shoulder each driver used, on average, during the two test periods. The results are mixed. Two of the six drivers used a greater percentage of the shoulder when the DAS was active and did so by a large percentage. Four of the drivers used less shoulder, but the difference was mostly minimal. Overall, drivers stayed in the shoulder 4.3 percent longer when the DAS was active. However, this change was not statistically significant at the $95 \%$ confidence level.

Increased speeds in the shoulder are another corollary of driver confidence. The maximum allowable shoulder speed for the buses is $35 \mathrm{mph}(56.3 \mathrm{~km} / \mathrm{hr})$. All six drivers drove faster in the shoulder when the DAS was in use. As Table 3 shows, two of the drivers increased their speeds by 6.1 and $7.7 \mathrm{mph}(9.8$ and $12.4 \mathrm{~km} / \mathrm{hr}$ ). The average increase was $3.5 \mathrm{mph}(5.6 \mathrm{~km} / \mathrm{hr})$, and this increase was statistically significant at the $95 \%$ confidence level.

Speed fluctuation also was examined. Large speed fluctuations are a sign of rapid acceleration and braking. The logic behind this measure was that the DAS would lead to less speed fluctuation. The measure of performance was the standard deviation from the average speed. As the standard deviation approaches zero, there is less fluctuation in speed. As shown in Table 4, three of the six drivers had slightly less standard deviation of speed, and three had slightly more. Overall, the standard deviation of speed with and without the DAS was roughly the same at about $4 \mathrm{mph}$ $(6.4 \mathrm{~km} / \mathrm{hr})$. The change was not statistically significant at the $95 \%$ confidence level.

\section{Technical Performance}

The technical performance component of the evaluation compared how well the buses stayed inside the shoulder with and without the DAS. This part of the evaluation required considerable thought because the DAS is a vehicle "assist," not an "automation" technology. This means the driver can chose to ignore the feedback from the DAS and drive at the offset he/she prefers. If, for example, a driver chooses to "hug" the fog line, it should not be counted against the performance of the DAS. The performance measure that was used was the standard deviation of average offset from the shoulder middle. This is a measure of the side-to-side movement of the bus. As the standard deviation approaches zero, there is less side-to-side move- 
Table 2. Percentage of Available Shoulder Used

\begin{tabular}{|c|c|c|c|c|}
\hline Driver & DAS Off (\%) & DAS On (\%) & Change (\%) & P Value \\
\hline 1 & 25.6 & 24.5 & -1.1 & $\mathrm{n} / \mathrm{a}$ \\
\hline 2 & 18.5 & 65.8 & +47.3 & $\mathrm{n} / \mathrm{a}$ \\
\hline 3 & 21.2 & 59.7 & +38.5 & $\mathrm{n} / \mathrm{a}$ \\
\hline 4 & 50.2 & 48.3 & -1.9 & $\mathrm{n} / \mathrm{a}$ \\
\hline 5 & 49.0 & 30.6 & -18.4 & $\mathrm{n} / \mathrm{a}$ \\
\hline 6 & 10.4 & 7.8 & -2.6 & $\mathrm{n} / \mathrm{a}$ \\
\hline Average & $\mathbf{2 9 . 7}$ & $\mathbf{3 4 . 0}$ & $\mathbf{+ 4 . 3}$ & $\mathbf{0 . 5 4 8}$ \\
\hline
\end{tabular}

*Not statistically significant at $95 \%$ confidence level.

Table 3. Average Speeds in the Shoulder

\begin{tabular}{|c|c|c|c|c|}
\hline Driver & DAS Off (mph) & DAS On $(\mathbf{m p h})$ & Change (mph) & P Value \\
\hline 1 & 31.0 & 37.1 & +6.1 & $\mathrm{n} / \mathrm{a}$ \\
\hline 2 & 29.3 & 32.2 & +2.9 & $\mathrm{n} / \mathrm{a}$ \\
\hline 3 & 31.0 & 33.1 & +2.1 & $\mathrm{n} / \mathrm{a}$ \\
\hline 4 & 31.3 & 31.4 & +0.1 & $\mathrm{n} / \mathrm{a}$ \\
\hline 5 & 29.6 & 37.3 & +7.7 & $\mathrm{n} / \mathrm{a}$ \\
\hline 6 & 33.2 & 34.0 & +0.8 & $\mathrm{n} / \mathrm{a}$ \\
\hline Average & $\mathbf{3 1 . 2}$ & $\mathbf{3 4 . 7}$ & $\mathbf{+ 3 . 5}$ & $\mathbf{0 . 0 3 8}$ \\
\hline
\end{tabular}

*Statistically significant at $95 \%$ confidence level.

Table 4. Standard Deviation of Speed

\begin{tabular}{|c|c|c|c|c|}
\hline Driver & DAS Off (mph) & DAS On (mph) & Change (mph) & P Value \\
\hline 1 & 3.9 & 3.3 & -0.6 & $\mathrm{n} / \mathrm{a}$ \\
\hline 2 & 2.4 & 3.0 & +0.6 & $\mathrm{n} / \mathrm{a}$ \\
\hline 3 & 3.4 & 1.9 & -1.5 & $\mathrm{n} / \mathrm{a}$ \\
\hline 4 & 5.2 & 5.3 & +0.1 & $\mathrm{n} / \mathrm{a}$ \\
\hline 5 & 7.2 & 5.3 & -1.9 & $\mathrm{n} / \mathrm{a}$ \\
\hline 6 & 2.9 & 3.8 & +0.9 & $\mathrm{n} / \mathrm{a}$ \\
\hline Average & $\mathbf{4 . 2}$ & $\mathbf{4 . 0}$ & $\mathbf{- 0 . 2}$ & $\mathbf{0 . 8 3 4}$ \\
\hline
\end{tabular}

*Not statistically significant at $95 \%$ confidence level. 
ment. Reducing side-to-side movement is important because the average shoulder width is 11 feet ( 3.35 meters), and the width of the bus is 9.5 feet ( 2.89 meters) from mirror to mirror. That leaves an 18-inch $(0.46 \mathrm{~m})$ margin of error. As Table 5 shows, five of the six drivers had less side-to-side movement when using the DAS. Overall, side-to-side movement was reduced by 4.7 inches, going from 17.6 to 12.9 inches (44.7 to $32.8 \mathrm{~cm}$ ), well below the 18-inch margin of error. This change was statistically significant at the $95 \%$ confidence level.

Table 5. Standard Deviation of Offset from Shoulder Center

\begin{tabular}{|c|c|c|c|c|}
\hline Driver & DAS Off (in.) & DAS On (in.) & Change (in.) & P Value \\
\hline 1 & 17.0 & 13.9 & -3.1 & $\mathrm{n} / \mathrm{a}$ \\
\hline 2 & 17.3 & 9.6 & -7.7 & $\mathrm{n} / \mathrm{a}$ \\
\hline 3 & 20.9 & 9.7 & -11.1 & $\mathrm{n} / \mathrm{a}$ \\
\hline 4 & 13.7 & 13.9 & +0.2 & $\mathrm{n} / \mathrm{a}$ \\
\hline 5 & 17.2 & 13.2 & -4.0 & $\mathrm{n} / \mathrm{a}$ \\
\hline 6 & 20.6 & 13.5 & -7.1 & $\mathrm{n} / \mathrm{a}$ \\
\hline Average & $\mathbf{1 7 . 6}$ & $\mathbf{1 2 . 9}$ & $\mathbf{- 4 . 7}$ & $\mathbf{0 . 0 0 0}$ \\
\hline
\end{tabular}

*Statistically significant at $95 \%$ confidence level.

\section{Bus Driver Satisfaction}

In the bus driver survey, 88 percent agreed or strongly agreed that the DAS was easy to use, and 64 percent agreed or strongly agreed that the DAS made driving in the shoulder less stressful. However, there were some negative comments in the focus groups. Many of the drivers indicated that the HUD was distracting. According to their testimony, there are too many things going on while driving in the shoulder to be able to focus on the head-up display (HUD) screen. Similar results were found from the survey question that asked drivers for their opinion of the various DAS components. As Table 6 shows, 40 percent disagreed or strongly disagreed that the HUD was helpful, and 48 percent disagreed or strongly disagreed that the steering wheel feedback was valuable. In contrast, the vibrating seat was highly regarded in both the survey and the focus groups. In the survey, 80 percent agreed or strongly agreed that the vibrating seat was valuable. In the focus groups, the vibrating seat was regarded as the best feature of the DAS because, as one driver put it, "It doesn't take your eyes off the road." 
Table 6. Survey Results of Driver Opinions about DAS Components

\begin{tabular}{|l|c|c|c|c|c|}
\cline { 2 - 6 } \multicolumn{1}{l|}{} & $\begin{array}{c}\text { Strongly } \\
\text { Agree (\%) }\end{array}$ & Agree (\%) & Disagree (\%) & $\begin{array}{c}\text { Strongly } \\
\text { Disagree (\%) }\end{array}$ & $\begin{array}{c}\text { Total } \\
\text { Responses }\end{array}$ \\
\hline $\begin{array}{l}\text { I find the head-up } \\
\text { display helpful. }\end{array}$ & 16 & 44 & 20 & 20 & 25 \\
\hline $\begin{array}{l}\text { I find the steering } \\
\text { wheel helpful. }\end{array}$ & 8 & 44 & 32 & 16 & 25 \\
\hline $\begin{array}{l}\text { I find the vibrating } \\
\text { seat helpful. }\end{array}$ & 24 & 56 & 8 & 12 & 25 \\
\hline $\begin{array}{l}\text { I find the virtual } \\
\text { mirror helpful. }\end{array}$ & 8 & 56 & 16 & 20 & 25 \\
\hline
\end{tabular}

Note: All 25 DAS-trained drivers responded to the survey. Margin of error is 0 points.

In terms of confidence, 32 percent of the drivers said they were more confident when driving in the shoulder with a DAS-equipped bus, and 60 percent said their confidence was the same. Similarly, 32 percent said they were more confident driving in the shoulder having completed DAS training, and 60 percent said their confidence was the same. A comment made by several drivers in the focus groups was that the DAS simulator was an excellent training tool for the newer drivers and that it helps to instill good driving habits.

\section{Safety}

The safety component of the evaluation looked at accident report data and survey data from the bus drivers. Accident data of the DAS-equipped buses was compared for the first six months of operations (November 2010 to April 2011) to the same six months from the previous year. The empirical data confirms that bus shoulder operations were and continue to be safe. There were zero accidents in the shoulder during both periods. As of September 2012 (17 months after the evaluation), there still had been no accidents in the shoulder with the DAS-equipped buses. In the bus driver surveys, 62.5 percent agreed or strongly agreed that the DAS made driving in the shoulder safer (see Table 7).

Table 7. Impacts of DAS on Perceptions of Safety

\begin{tabular}{|c|c|c|c|c|c|}
\hline Question & $\begin{array}{c}\text { Strongly } \\
\text { Agree (\%) }\end{array}$ & Agree (\%) & Disagree (\%) & $\begin{array}{c}\text { Strongly } \\
\text { Disagree (\%) }\end{array}$ & $\begin{array}{c}\text { Total } \\
\text { Responses }\end{array}$ \\
\hline $\begin{array}{l}\text { The DAS makes driving } \\
\text { in the shoulder safer. }\end{array}$ & 12.5 & 50.0 & 20.8 & 16.7 & 24 \\
\hline
\end{tabular}

Note: All 25 DAS-trained drivers responded to the survey. Margin of error is 0 points. 


\section{Customer Satisfaction}

This part of the evaluation sought to find out whether the presence of the DAS influenced any passengers to switch to transit and whether any of the passengers could detect a change in ride quality when the DAS was used. The survey revealed that 11.9 percent of the passengers said they were influenced to try transit because of the presence of the DAS. Most likely, they were influenced by the "Bus 2.0" wrap that was featured on the outside of the buses, as shown in Figure 2.

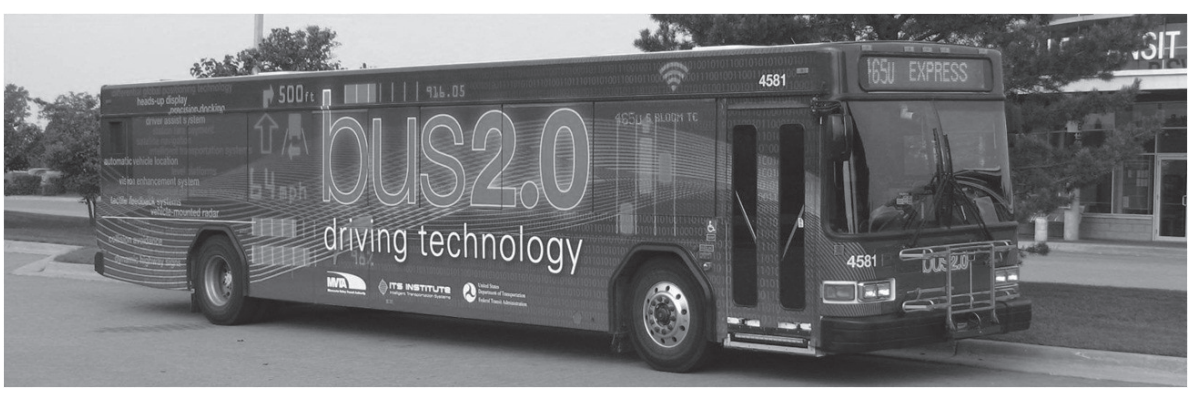

\section{Figure 2. "Bus 2.0" Wrap}

Riders were asked to rate various aspects of the ride quality of the bus such as merging in and out of the shoulder, vehicle swaying, accelerating/decelerating, and overall smoothness of the ride. As shown in Table 8, more than 80 percent of passengers rated these aspects as very good or good.

\section{Table 8. Customer Comments about Ride Quality}

How would you rate the quality of each of the following aspects of the ride when the bus
is on the shoulder?
\begin{tabular}{|l|c|c|c|c|c|c|}
\hline & $\begin{array}{c}\text { Very } \\
\text { Good (\%) }\end{array}$ & $\begin{array}{c}\text { Good } \\
(\%)\end{array}$ & $\begin{array}{c}\text { Fair } \\
(\%)\end{array}$ & $\begin{array}{c}\text { Poor } \\
(\%)\end{array}$ & $\begin{array}{c}\text { Very } \\
\text { Poor (\%) }\end{array}$ & $\begin{array}{c}\text { Don't } \\
\text { Know (\%) }\end{array}$ \\
\hline Merging in/out of shoulder & 52.2 & 34.3 & 5.2 & 1.5 & 0.0 & 6.7 \\
\hline Swaying of bus & 49.3 & 35.1 & 8.2 & 2.2 & 0.0 & 5.2 \\
\hline Accelerating / decelerating & 43.6 & 39.1 & 9.8 & 2.3 & 0.8 & 4.5 \\
\hline Overall smoothness of ride & 49.3 & 34.3 & 10.4 & 0.7 & 0.7 & 4.5 \\
\hline
\end{tabular}

Margin of Error: \pm 7 percent at the 95 percent confidence level.

\section{Maintenance}

The intent of the maintenance portion of the evaluation was to measure the level of effort required to maintain and repair the DAS. The measure of effectiveness was the number of hours/days the DAS was down for repair. A maintenance log was 
kept by the system integrator, the Intelligent Vehicles Laboratory at the University of Minnesota, which includes date/timestamps for each time a problem with the DAS was reported and for when the repair was completed. Based on a review of the maintenance log, the 10-vehicle DAS fleet was operative 91.9 percent of the time during the evaluation period. The most frequently cited malfunction was a lack of feedback to the vibrating seat.

\section{Conclusion}

The Cedar Avenue DAS is the first lane-keeping application of vehicle assist and automation technology (VAA) in bus revenue service by a U.S. transit system. MVTA's primary goal for implementing the DAS was to enhance driver confidence in the shoulders. Their secondary goals included reducing travel times and increasing reliability, safety, and customer satisfaction. This report is the first comprehensive evaluation of VAA technology in the U.S. and confirms that VAA technologies such as the DAS can improve bus operations and reduce driver stress. When the DAS was activated, bus drivers stayed in the shoulders 4.3 percent longer and drove 3.5 miles per hour faster. Lateral (side-to-side) movement was reduced by 4.7 inches. The increase in speed and the decrease in lateral movement were both statistically significant at the $95 \%$ confidence level. A total of 32 percent of bus drivers said their level of confidence in driving in the shoulder was greater when using the DAS, and 60 percent said it was the same. These results suggest that the DAS may not have influenced the extent to which the drivers used the shoulder, but it did improve their driving performance when they were in the shoulder. The majority of drivers believed the DAS made driving in the shoulder safer and less stressful. During the evaluation, there were zero accidents in the shoulder with DAS-equipped buses and, as of September 2012 (17 months later), there still had been no accidents. Nevertheless, many drivers raised concerns about one of the components-the head-up display-being a distraction. For customer satisfaction, more than 80 percent of surveyed passengers rated the ride quality in the shoulder as very good or good. For maintenance, a review of the maintenance logs showed that the buses were operative 91.9 percent of the time.

\section{Acknowledgment}

The authors wish to acknowledge the funding support of the Federal Transit Administration through the National Bus Rapid Transit Institute for the conduct of this research. 


\section{References}

Advanced Public Transport Systems. The Eindhoven project in The Netherlands, http://www.apts-phileas.com, accessed July 27, 2011.

Bishop, R. 2000. A Survey of intelligent vehicle applications worldwide. Presented at IEEE Intelligent Vehicles Symposium, Dearborn, MI.

Brown, T., J. Moeckli, and D. Marshall. 2009. Use of high-fidelity simulation to evaluate driver performance with vehicle automation systems. Engineering Psychology and Cognitive Ergonomics 5639: 339-348.

Boegner, J., and U. Koch. 1984. Dual-mode buses in the city of Essen, West Germany. Journal of Advanced Transportation 18(2): 163-183.

Furukawa, Y. 2000. Status and future direction of intelligent drive assist technology. Presented at IEEE Intelligent Transportation Systems Conference, Dearborn, MI.

Griffiths, P., and R. Gillespie, R. 2004. Shared control between human and machine: Haptic display of automation during manual control of vehicle heading. Presented at 12th International Symposium on Haptic Interfaces for Virtual Environment and Teleoperator Systems.

Hardy, M., and S. Proper. 2006. Analyzing the impacts of vehicle assist and automation systems on BRT. Journal of Public Transportation 9(3): 51-68.

Kim, E., J. Darido, and D. Schneck. 2005. Las Vegas Metropolitan Area Express (MAX) BRT Demonstration Project Evaluation. Publication FTA VA-26-72222005.1. Federal Transit Administration, Washington, D.C.

Levinson, H., et al. 2003. Bus rapid transit, Volume 1: Case studies in bus rapid transit, Appendix B. TCR P Report 90, Transportation Research Board.

Pessaro, B. 2011. An evaluation of the cleveland healthline mechanical guide wheel. Publication FTA- FL- 26-7110.2011.2. Federal Transit Administration, Washington, D.C.

Shladover, S. and M. Miller. 2004. Evaluation of lane-assist systems for urban transit operations. Presented at IEEE Intelligent Transportation Systems Conference, Washington, D.C. 
Shladover, S., et al. 2007. Lane assist systems for bus rapid transit, Volume I: Technology assessment. Publication RTA 65A0160, U.S. Department of Transportation, Washington, D.C.

Tan, H., et al. 2008. Field demonstration and tests of lane-assist/guidance and precision docking technology. Publication UCB-ITS-PRR-2009-12. University of California, Berkeley.

\section{About the Author}

Brian Pessaro (pessaro@cutr.usf.edu) is a senior research associate with the National Bus Rapid Transit Institute, Center for Urban Transportation Research, at the University of South Florida in Tampa. 